\title{
Evaluating efficiency of renewable energy sources in planning micro-grids considering uncertainties
}

\author{
$\mathrm{Vu}$ Van Thang \\ Thainguyen University of Technology, Thainguyen City, Vietnam, thangvvhtd@ tnut.edu.vn \\ ORCID: 0000-0002-4440-749X \\ Nguyen Hien Trung \\ Thainguyen University of Technology, Thainguyen City, Vietnam, nguyenhientrung@tnut.edu.vn \\ ORCID: 0000-0001-8329-7097
}

Arrived: 03.01.2019 Accepted: 14.01.2019 Published: 31.03.2019

\begin{abstract}
Nowadays, the renewable energy sources (RES) are widely utilized in micro-grids due to technical development and emission increase, which make the planning the micro-grids integrated the RES very important. To obtain the optimal planning strategy and evaluating efficiency of the RES in micro-grids, a mixed integer programming (MIP) planning framework for a gridconnected micro-grid is presented in this study. The understudy micro-grid consists of the wind turbines and photovoltaic systems, which are connected to utility grid through the point of common coupling (PCC). The objective function is minimizing the life cycle cost of object comprising of the investment and operation cost of the RES, the energy purchased cost from the utility grid, the emission taxes cost and the replacement cost or residual value of equipment at the end of the planning period. The uncertainties of load, electrical price, wind speed and solar radiation are taken into consideration and then a combinable model with the clustering technique is utilized to integrate them. Finally, numerical simulations for a test grid-connected micro-grid are made to validate the effectiveness of the proposed model and show efficiency of the RES to can apply to practical micro-grids.
\end{abstract}

Keywords: Emission, Life cycle cost, Micro-grids planning, Renewable energy sources, Uncertainties

Cite this paper as: $\quad$ planning micro-grids considering uncertainties. Journal of Energy Systems, 2019; 3(1): 14-25, DOI: https://dx.doi.org/10.30521/jes.507434 


\section{INTRODUCTION}

In recent decades, the demand in electricity increased while awareness of environmental protection increased as well, ensuing in a pledge to cut high emissions of traditional resources. Therefore, renewable energy sources are widely used as a result of this trend. They are connected to the low and medium voltage distribution system and create a new structure called micro-grid [1],[2]. A micro-grid can be designed to operate in either grid-connected or standalone mode. In grid-connected mode, the load can be supplied from both the renewable energy sources and diesel generators as well as from the utility grid through the point of common coupling (PCC) [[3],[4]]. The main benefit of this micro-grid mode is that it can still operate in a standalone mode when the connection to the utility grid is interrupted. The reliability of micro-grids is improved though the renewable sources cannot guarantee to supply power for the all of the load. Therefore, micro-grids are very promising to obtain an optimal planning strategy, evaluate efficiency of the RES and develop a green and sustainable energy system.

Many techniques of the RES have been researched, developed and applied in practice as photovoltaic panels, wind turbines, biogas-based internal combustion generators and micro-hydro generators with power less than 5MW [[5],[6]]. In recent years, the most popular renewable energy techniques have been the wind turbines (WT) and photovoltaic systems (PV) because they have the large potential, lower emissions and levelised cost of electricity than fossil fuel options [8]. Moreover, the various advantages when the RES integrated in optimal planning the micro-grids and distributed systems include the cost decrease, improved energy efficiency and higher resiliency, increased reliability, reduction in transmission losses and upgraded feeder deferment, emission reduction and a more flexible operation [9]-[11].

Because of all those reasons, numerous studies for planning, designing and operating of micro-grids considering the RES have been introduced in recent years [7,[12]. The optimal planning of isolated micro-grids with renewable energy resources handled through demand response or controllable loads is introduced in studies [13]. Their objective function includes the annual average cost of the initial investment, the cost replacement, operation, maintenance and demand response compensation or salvage value and power shortage penalty. Energy storage systems like the battery or pumped storage are utilized to guarantee supplying energy for any load, even when the output power of the RES is intermitted. In study [14], the grid-connected micro-grids planning process is presented with the objective to minimalize the total cost of planning project comprising of the investment and operation cost. All of them are the present-worth values because of discount rate in objective function. Similarly, a generation-side power scheduling and economic dispatch of distributed generators to grid-connected micro-grid is also represented in study [15]. The objective is to minimize operation costs that the user must pay for such as energy provided by the sources. The analyzed parameters of the micro-grid are assumed as unchanged values in these studies, despite of that they may be natural intermittent and are uncertain parameters, thus the error of the calculation result is often high.

To overcome those disadvantages, the uncertainties of the wind speed, natural gas price and annual load are represented by three values corresponding to probability of them. They are examined in an optimal model to design and operate a grid-connected micro-grid with objective function to minimize the overall cost of the electrical power, the fuel and incentive based demand response program [16]. However, the small state number and the ignored investment cost of distributed energy resources are limitations of this study. The planning models considering stochastic characteristic are introduced in study [17]. The objective function includes the equivalent annual value of investment cost, annual maintenance cost, fuel cost and environmental cost. Besides, the energy loss cost, energy not supplies cost and improving total voltage profile index are added in model of study [18]. Although these models do examine of equipment investment cost, the difference of lifetime and uptime of them is ignored in this study. The planning frameworks considering the uncertain parameters, lifetime of equipment and planning period 
are presented in studies [20]-[22] with components of objective function that are the capital cost, operation and maintenance cost, replacement and salvage costs of the equipment at the end of the project. The unserved energy and reliability constraints are also considered to improve economic effectiveness and reliability of micro-grids. In addition, for a short planning period of micro-grid, the optimization method with an objective function based on minimal life cycle cost (LCC) is introduced in studies [23],[24] which aims to improve the effectiveness of the micro-grid planning problem. In these models, the LCC optimization theory is applied to take into consideration the cost during the entire duration of the project including the capital investment, the operation and maintenance cost, the recycling profit of scrapped equipment, the pollutant emission compensation cost and the energy shortage compensation cost. Those parameters of the simulation are unchanged values in this study, leading to a significant error of calculation result.

As described in detail above, the aspects of the micro-grid planning problem like uncertainty of parameters, investment and operation cost, replacement and salvage costs, lifetime of equipment and emission cost are studied and examined in optimal models. However, in each study, only several aspects are considered and that are the limitations of the present studies. Additionally, the decision variables utilized to select the power and capacity of the equipment are often continuous variables, despite being discrete values in fact. Because of those reasons, this study proposes a structure of grid-connected microgrid, which can integrate and evaluate the efficiency of the RES in a scenario interested in the uncertainty of parameters. Then, an optimal model to plan the proposed micro-grid is created with a LCC objective function and constrains, which considers the uncertainty of the parameters as well as equipment lifetime and planning period of the project. The uncertainty of parameters is modeled by the probability density functions (pdf), the K-means clustering technique is utilized to divide into states and then a combinable model are applied to integrate in all states in the planning model. The binary variables are utilized in the model to select the rated sizes of equipment based on standard values and thus the results will be more accurate and the applicability of them in practice will be higher.

This study presents the modeling of those uncertainty parameters in Section 2, a detail description of the planning model in Section 3. The numerical simulations for computed cases are illustrated in Section 4 and the conclusions are given in Section 5.

\section{STRUCTURE OF MICRO-GRID AND MODELING UNCERTAINTY OF PARAMETERS}

\subsection{Structure of micro-grid}

To evaluate the efficiency of the RES in planning micro-grids, a grid-connected micro-grid with a structure shown in figure 1 is proposed. The demand of the load is supplied from the utility grid through PCC and RES. The PV and WT are chosen to examine further because of their great potential and it is easy to connect to the micro-grid. This structure has high reliability, the output power of the RES is not limited and thus the effectiveness of the RES is improved. 


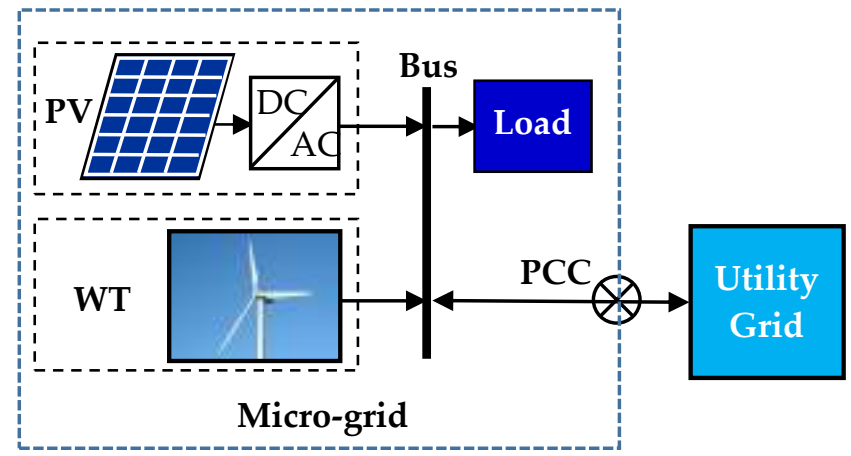

Figure 1. Structure of grid-connected micro-grid

\subsection{Modeling uncertainty of parameters}

As can be seen from figure 1, the uncertain parameters of the proposed micro-grid are the output power of the PV and WT, load and electrical price. The random change of them is modeled by the pdf and then the clustering technique is utilized to divide stochastic parameters into different states with specific values and their related probability in each state [23]-[27].

The randomness of solar irradiate is modeled by the beta distribution as in equation (1). $I_{i r}$ is the solar irradiate at each state, $\mu$ is the mean and $\sigma$ is the standard deviation of the stochastic variable [[18],[20],[28]]. In each state, the output power of the PV is calculated under the rated power $P_{r}^{P V}$ at the standard test condition, solar irradiate and the operating ambient temperature as (2). In which, the standard test condition means that solar irradiate $I_{\text {ir.stc }}$ is $1000 \mathrm{~W} / \mathrm{m}^{2}$ and temperature $T_{\text {stc }}$ is $25^{\circ} \mathrm{C}, I_{\text {ir.s }}$ is the irradiate and $T_{c . s}$ is temperature of $\mathrm{PV}$ at operating state, and $k_{T}$ is the power temperature coefficient of the PV.

$$
\begin{gathered}
f_{b}\left(I_{i r}\right)=\left\{\begin{array}{lc}
\frac{\Gamma(\alpha+\beta)}{\Gamma(\alpha) \cdot \Gamma(\beta)} \cdot I_{i r}^{(\alpha-1)} \cdot\left(1-I_{i r}\right)^{(\beta-1)} \text { if } 0 \leq I_{i r} \leq 1 \\
0 & \text { else }
\end{array}\right. \\
\beta=(1-\mu) \cdot\left(\frac{\mu \cdot(1+\mu)}{\sigma^{2}}-1\right) ; \quad \alpha=\frac{\mu \cdot \beta}{1-\mu}
\end{gathered}
$$

Similarly, the stochastic behavior of wind speed $v$ is modeled by weibull distribution shown in expression (3) with the shape index $k$ and the scale index $c$ [[18],[20],[28]]. In each state s of wind speed, the output power of the WT is determined in equation (4) with output power $P_{s}^{W T}$, rated power $P_{r}^{W T}$, cut-in speed $v_{c i}$, rated speed $v_{c r}$, and cut-off speed $v_{c o}$ of WT.

$$
f_{r}(v)=\frac{k}{c}\left(\frac{v}{c}\right)^{k-1} \cdot \exp \left(-\left(\frac{v}{c}\right)^{k-1}\right) ; \quad c=\frac{\mu}{\Gamma\left(1+\frac{1}{k}\right)} ; \quad k=\left(\frac{\sigma}{\mu}\right)^{-1.086}
$$




$$
P_{s}^{W T}(v)= \begin{cases}0 & v_{s} \leq v_{c i} \text { or } v_{c o} \leq v_{s} \\ P_{r}^{W T} \cdot \frac{v_{s}-v_{c i}}{v_{r}-v_{c i}} & v_{c i} \leq v_{s} \leq v_{r} \\ P_{r}^{W T} & v_{r} \leq v_{s} \leq v_{c o}\end{cases}
$$

The normal distribution is utilized to model the stochastic change of the load as present in equation (5) , where $x$ is the load power, $\mu$ is the mean of the distribution, $\sigma$ is the standard deviation and $\sigma^{2}$ is variance of the load at each state s [[17],[18]]. Analogously, the electricity price of the competitive market is also a stochastic parameter and expressed by the normal distribution in equation (5)[[29],[31]] with $x$ for the value of the electrical price at state $\mathrm{s}$.

$$
f(x)=\frac{1}{\sigma \sqrt{2 \pi}} \exp \left[-\frac{(x-\mu)^{2}}{2 \sigma^{2}}\right]
$$

The multi-state parameters of the micro-grid as the output power of the PV and WT, load and electrical price are integrated by a combinable model introduced in studies [[31],[31]]. A matrix is utilized to enumerate all combination of states of parameters as equation (6) with $C_{\mathrm{s}}$ as the matrix enumeration the possible values of parameters. $\lambda_{s}\left\{\mathrm{C}_{s}\right\}$ is a one-column matrix representing probability corresponding with the matrix $C_{s}$ and $N_{\mathrm{s}}$, which is the sum of individual states of the matrix $\boldsymbol{M}$, is computed by product the possible states of the parameters.

$$
\begin{aligned}
& M=\left\{\mathrm{C}_{s}, \lambda_{s}\left\{\mathrm{C}_{s}\right\}\right\} \\
& \lambda_{s}\left\{\mathrm{C}_{s}\right\}=\lambda_{s}^{\rho}\left\{\rho_{s}\right\} \cdot \lambda_{s}^{L}\left\{P_{s}^{L}\right\} \cdot \lambda_{s}^{\mathrm{W} T}\left\{P_{s}^{\mathrm{W} T}\right\} \cdot \lambda_{s}^{P V}\left\{P_{s}^{P V}\right\} \\
& N_{s}=n_{s}^{\rho} \cdot n_{s}^{L} \cdot n_{s}^{\mathrm{W} T} \cdot n_{s}^{P V} \\
& \forall s \in N_{s}
\end{aligned}
$$

Where, $\rho_{s}$ and $P_{s}^{L}$ are the electricity price and load corresponding with probabilities $\lambda_{s}^{\rho}$ and $\lambda_{s}^{L}$, respectively. The $P_{s}^{W T}, P_{s}^{P V}$ are the output power of WT and PV corresponding with probabilities $\lambda_{s}^{\mathrm{wT}}$ and $\lambda_{s}^{P V}$, respectively. The $n_{s}^{\lambda}, n_{s}^{L}$ are the numbers of states assumed of the electricity price and load while the $n_{s}^{W T}, n_{s}^{P V}$ that are the numbers of states of the output power of RS, respectively.

The numbers of scenarios to calculate $N_{S}$ are very big depending on the chosen number of states in each pdf. Choosing the number of states is very important because of its effect on the accuracy of results and the complexity of the calculation. When numberous of scenarios selected, the accuracy is higher but computational burdens increase and vice versa.

\section{MATHEMATICS MODEL}

An optimal model is introduced with the LCC objective function including the investment cost, replacement cost or residual value of the RES at the end of planning period, operation and maintenance cost, and reduced emission cost of micro-grid during time the project. The micro-grid operation cost includes that of the RES plus the cost of energy purchase from the utility grid with the market price at the PCC. The reduced emission cost of micro-grids is calculated based on the difference in emissions between traditional energy sources and the RES. The objective function is evaluated in terms of 
discounted costs, where discount rates are incorporated in the present-worth cost components as presented in equation (7).

$$
\operatorname{Min} \sum_{t=1}^{T} \frac{1}{(1+r)^{t}}\left(C_{I . t}^{R}+C_{O M . t}^{R}+C_{E . t}^{G}-B_{E m i . t}-B_{R e s . t}\right)
$$

Where, the $C_{I . t}^{R}$ is the investment cost and $C_{O M . t}^{R}$ is the operation and maintenance of the RES. The $C_{E . t}^{G}$ is the cost for purchasing energy from the utility grid, the $B_{E m i . t}$ is the benefit or reduced cost due to decrease of emission taxes of the RES. $B_{\text {Res.t }}$ is the residual value or replacement cost of the RES at the end of the project, $r$ is discount rate and $T$ is the total planning time.

The investment cost of the RES is analyzed in equation (8) with capital cost $C_{k}^{R}$ and invested power $P_{I ., k, t}^{R}$ of the RES technology $\mathrm{k}$ at the year $\mathrm{t}$ that depends on rated powers, which is discrete values and the binary variable $\alpha_{i . k}$ in constraint (15). $N_{k}$ is total number of RES technologies considered for investment.

$$
C_{I . t}^{R}=\sum_{k=1}^{N_{K}} C_{k}^{R} \cdot P_{I . k, t}^{R} \quad \forall t \in T
$$

The operation and maintenance cost of the RES is analyzed based on average cost of an electrical energy unit that the RES generate in equation (9). Where, $\rho_{O M . k}^{R}$ is the coefficient for determining the operation and maintenance cost, $P_{k, t}^{R}$ is the power of the RES with type $\mathrm{k}$ at the year $\mathrm{t}, \lambda_{s}$ is probability in state $\mathrm{s}$, and $k_{k, s}^{R}$ is the output power factor of the RES type $\mathrm{k}$ in state s. Similarly, the cost of electrical energy purchased from the utility grid depends on the power received through PCC $P_{t, s}^{G}$ in state s in equation (10) with the electrical energy price $\rho_{E}^{G}$ and the annual rise factor of it $k_{\rho}$.

$$
\begin{array}{cc}
C_{O M . t}^{R}=8760 \sum_{k=1}^{N_{K}} \sum_{s=1}^{N_{S}} \rho_{O M . k}^{R} \cdot \lambda_{s} \cdot k_{k, s}^{R} \cdot P_{k, t}^{R} & \forall t \in T \\
P_{k, t}^{R}=P_{k, t-1}^{R}+P_{I . k, t}^{R} & \forall t \in T \\
C_{E . t}^{G}=\sum_{s=1}^{N_{S}} k_{\rho} \cdot \rho_{E}^{G} \cdot \lambda_{s} \cdot P_{t, s}^{G} & \forall t \in T
\end{array}
$$

The emission of the RES is lower than the traditional energy sources and thus the emission of microgrids reduces when the RES are invested and the cost for emission taxes diminishes. The benefit due to decrease of the emission taxes very year is computed by equation (11). Where, $\xi_{G}$ and $\xi_{R S}$ are $\mathrm{CO}_{2}$ emission coefficients of traditional sources and the RES, respectively, and $\beta$ is the emission tax probably enforced by the government.

$$
B_{E m i . t}=\beta \cdot\left(\xi_{G}-\xi_{R S}\right) .8760 . \sum_{k=1}^{N_{K}} \sum_{s=1}^{N_{S}} \lambda_{s} \cdot k_{k, s}^{R} \cdot P_{k, t}^{R} \quad \forall t \in T
$$


Analyzing the replacement cost or residual value of the RES at the end of the planning period is computed by expression (12) with the lifetime, $T_{c . k}^{R}$, the installed time $t_{I . k}^{R}$ and the uptime $t_{u p . k}^{R}$. At the end of the analyzing time, if the uptime of the RES is shorter than the lifetime of them, $B_{\text {Res.t }}$ is the residual value and it becomes the replacement cost on the contrary.

$$
\begin{array}{ll}
B_{R e s . t}=\frac{T_{c . k}^{R}-t_{u p . k}^{R}}{T_{c . k}^{R}} C_{I . t}^{R} & \forall t \in T, k \in N_{K} \\
t_{u p . k}^{R}=T-t_{I . k}^{R} & \forall k \in N_{K}
\end{array}
$$

The power balance constraint of the micro-grid in each state $s$ as represented in equation (13) consist of the purchased power from the utility grid $P_{t, s}^{G}$, the output power of the RES and the load power. Where, the $k_{s}^{L}$ is the load factor at each state s and $P_{t}^{L}$ is load power at the year t determined in equation (14). $P_{0}^{L}$ is the load value at base year and $k_{g}^{L}$ is annual growth factor of the load.

$$
\begin{gathered}
P_{t, s}^{G}+\sum_{k=1}^{N_{K}} k_{k, s}^{R} \cdot P_{k, t}^{R}=k_{s}^{L} \cdot P_{t}^{L} \quad \forall t \in T, s \in N_{S} \\
P_{t}^{L}=P_{t-1}^{L} \cdot\left(1+k_{g}^{L}\right) \quad \forall t \in T
\end{gathered}
$$

In fact, the RES are manufactured in modules with different rate powers, which are discrete values. Therefore, the integer variables $\alpha_{i, k}$ are utilized in constrain (15) to select the optimal number, rated power and of module types of the RES with the rated power of each technology $\mathrm{k}$ and module $P_{r ., i}^{R}$. The power of the RES that can be harvested depends on the potential of the primary energy source in the micro-grid and thus the total power limit of each technology is constrained by equation (17) with $P_{k \cdot m a x}^{R}$ that is limit power of each technology $\mathrm{k}$.

$$
\begin{array}{cc}
P_{I . k, t}^{R}=\alpha_{k, i} P_{r . k, i}^{R} & \forall t \in T, k \in N_{K} \\
\sum_{t=1}^{T} P_{I ., t}^{R} \leq P_{k . \max }^{R} & \forall k \in N_{K}
\end{array}
$$

The maximum penetration of the RES in the micro-grid is limited based on the load power with the factor $x$ in equation (17). This constraint guarantees that the power flow is always from the utility grid to micro-grid and thus the protection relay system is simpler. The power and energy that a micro-grid can be received from utility grid is assumed to be unlimited, because the power of the utility grid is much larger than power of micro-grids. However, the constraint (18) guarantees the equipment of the PCC not to be overload with $S_{\max }^{P C C}$ as maximum capacity.

$$
\sum_{t=1}^{T} \sum_{k=1}^{N_{K}} P_{I . k, t}^{R} \leq x . P_{t}^{L}
$$




$$
P_{t, s}^{G} \leq S_{\max }^{P C C} \quad \forall t \in T, s \in N_{S}
$$

The defined problem is a MIP model and is simulated for test micro-grid using GAMS/CPLEX software as below.

\section{RESULTS and DISCUSSIONS}

\subsection{The parameters of test micro-grid}

The test micro-grid has a structure as seen in figure 1. It is simulated with a load of $850 \mathrm{~kW}$ in base year and grows 5\% annually. The rated power and module type of the PV and WT are discrete values and are assumed in table 1 [[32]-[36]]. Analogously, the parameters of the utility grid are also presented in table 1 with an $\mathrm{CO}_{2}$ emission tax probably enforced by the government of $0.4 \mathrm{cent} / \mathrm{kg}$ [[38],[38]]. The simulation period is 10 years and the discount rate is $10 \%$.

The stochastic data of the load, output power of the PV and WT, and the electrical price are assumed and expressed by the pdf. Then K-means clustering technique is applied to divide into discrete values corresponding to each state $\mathrm{s}$ as shown in table 2 [[40],[40]]. The combinable model introduced in section 2 allows integration of all states and makes $11^{4}$ (14641) scenarios [[26],[27],[29]].

Table 1. Parameters of the RES and the utility grid

\begin{tabular}{|c|c|c|c|c|c|}
\hline $\mathrm{PV}$ & & WT & & Utility grid & \\
\hline $\begin{array}{ll}\text { Rated } & \text { power, } \\
P_{r . k, i}^{R} & \end{array}$ & $\begin{array}{l}50 ; 100 ; 120 ; 150 ; 200 ; \\
250 ; 300 ; 350 ; 430 ; 500 \\
\text { kW }\end{array}$ & $\begin{array}{l}\text { Rated } \\
P_{r . k, i}^{R}\end{array}$ & $\begin{array}{l}100 ; 120 ; 150 ; 195 ; 225 \\
255 ; 360 ; 420 ; 480 ; 510 \\
\mathrm{~kW}\end{array}$ & $\begin{array}{l}\text { Limited } \\
\text { capacity, } S_{\max }^{P C C}\end{array}$ & $\begin{array}{l}1000 \\
\mathrm{kVA}\end{array}$ \\
\hline $\begin{array}{l}\text { Capital } \\
C_{k}^{R}\end{array}$ & $1500 \$ / \mathrm{kW}$ & $\begin{array}{l}\text { Capital } \\
C_{k}^{R}\end{array}$ & $1800 \$ / \mathrm{kW}$ & $\begin{array}{l}\text { Electrical price, } \\
\rho_{k}^{G}\end{array}$ & $\begin{array}{l}0.15 \\
\$ / \mathrm{kWh}\end{array}$ \\
\hline $\begin{array}{l}\mathrm{O \& M} \\
\rho_{O M . k}^{R}\end{array}$ & $0.025 \$ / \mathrm{kWh}$ & $\begin{array}{l}\text { O\&M } \\
\rho_{O M . k}^{R}\end{array}$ & $0.035 \$ / \mathrm{kWh}$ & $\begin{array}{l}\text { Rise factor of } \\
\text { price, } k_{\rho}\end{array}$ & $1 \%$ \\
\hline $\begin{array}{l}\text { Emission } \\
\text { coefficient, } \xi_{\mathrm{R}}\end{array}$ & $0.025 \mathrm{~kg} / \mathrm{kWh}$ & $\begin{array}{l}\text { Emission } \\
\text { coefficient, } \xi_{\mathrm{R}}\end{array}$ & $0.02 \mathrm{~kg} / \mathrm{kWh}$ & $\begin{array}{l}\text { Emission } \\
\text { coefficient, } \xi_{\mathrm{G}}\end{array}$ & $\begin{array}{l}0.62 \\
\mathrm{~kg} / \mathrm{kWh}\end{array}$ \\
\hline Lifetime, $T_{c . k}^{R}$ & 30 year & Lifetime, $T_{c . k}^{R}$ & 25 year & & \\
\hline
\end{tabular}

\subsection{Calculated results}

The feasibility of the planning model and the efficiency of the RES in grid-connected micro-grid are investigated in two cases: In the first one, the micro-grid only purchases power from the utility gird (called without RES) and in the second one, the RES are additionally invested in the micro-grid to compare with the first case (called with RES).

Table 3 presents the invested decision of the RES in planning period with the number, rated power and type of modules, and installed time. Two PV modules with rated power of $250 \mathrm{~kW}$ are selected to invest. They have a total rated power installed $500 \mathrm{~kW}$ in the seventh year. Hence, the electrical energy purchased from the utility grid reduces $29.41 \%$ as shown in figure 2 . Similarly, the only one module of WT has a rated power of $510 \mathrm{~kW}$ and is implemented during time of project and it is installed at the eighth year. Total rated power of the RES is $1010 \mathrm{~kW}$ corresponding to $84.45 \%$ of peak load of the micro-grid at eighth year. 
Table 2. Probability of parameters

\begin{tabular}{lllllllll}
\hline \multirow{2}{*}{ State } & PV & & WT & \multicolumn{3}{c}{ Load } & \multicolumn{3}{c}{ Electrical price } \\
& $k_{s}^{R S}$ & $\lambda_{s}^{P V}$ & $k_{s}^{R S}$ & $\lambda_{s}^{W T}$ & $k_{s}^{L}$ & $\lambda_{s}^{L}$ & $k_{s}^{\rho}$ & $\lambda_{s}^{\rho}$ \\
\hline 1 & 1 & 0.014 & 1 & 0.007 & 1 & 0.01 & 1 & 0.028 \\
2 & 0.9 & 0.024 & 0.95 & 0.025 & 0.85 & 0.056 & 0.90 & 0.043 \\
3 & 0.8 & 0.069 & 0.85 & 0.032 & 0.77 & 0.106 & 0.80 & 0.085 \\
4 & 0.7 & 0.087 & 0.75 & 0.045 & 0.71 & 0.165 & 0.75 & 0.096 \\
5 & 0.6 & 0.081 & 0.65 & 0.051 & 0.65 & 0.165 & 0.70 & 0.129 \\
6 & 0.5 & 0.073 & 0.55 & 0.077 & 0.59 & 0.163 & 0.65 & 0.142 \\
7 & 0.4 & 0.052 & 0.45 & 0.091 & 0.51 & 0.163 & 0.60 & 0.137 \\
8 & 0.3 & 0.045 & 0.35 & 0.112 & 0.45 & 0.091 & 0.55 & 0.126 \\
9 & 0.2 & 0.031 & 0.20 & 0.103 & 0.41 & 0.047 & 0.50 & 0.102 \\
10 & 0.1 & 0.028 & 0.15 & 0.101 & 0.35 & 0.034 & 0.45 & 0.081 \\
11 & 0 & 0.497 & 0 & 0.354 & 0.30 & 0.00 & 0.40 & 0.031 \\
\hline
\end{tabular}

Table 3. Invested decision of the RES

\begin{tabular}{lllll}
\hline $\begin{array}{l}\text { Types of } \\
\text { the RES }\end{array}$ & $\begin{array}{l}\text { Number of } \\
\text { modules }\end{array}$ & $\begin{array}{l}\text { Rated power of } \\
\text { module, } P_{r, k, i}^{R}(\mathrm{~kW})\end{array}$ & $\begin{array}{l}\text { Total power, } \\
P_{I . k, t}^{R}(\mathrm{~kW})\end{array}$ & $\begin{array}{l}\text { Planning } \\
\text { year }\end{array}$ \\
\hline PV & 2 & 250 & 500 & 7 \\
WT & 1 & 510 & 510 & 8 \\
\hline
\end{tabular}

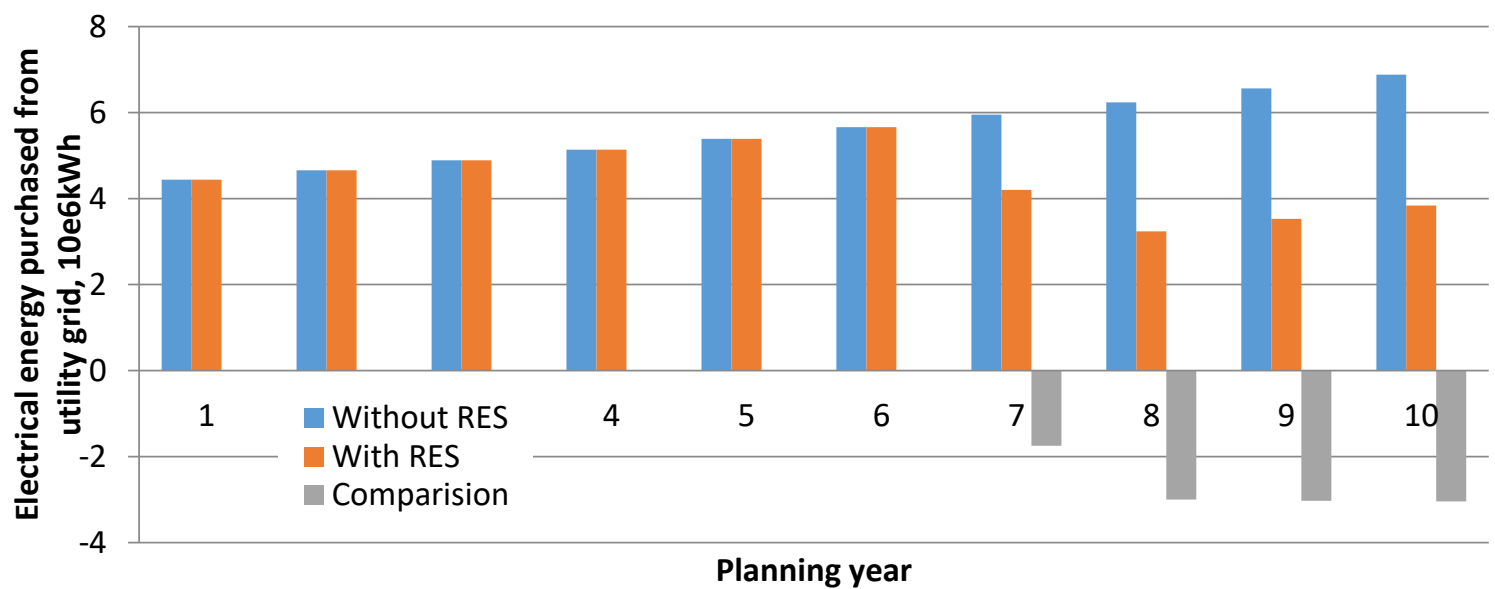

Figure. 2. Electrical energy purchased from the utility grid

When the RES are installed, the electrical energy purchased from the utility grid significantly reduces as shown in figure 2 . In the case without RES, it is $4.44 \times 10^{6} \mathrm{kWh}$ in the first year and increases to $6.88 \times 10^{6} \mathrm{kWh}$ in the tenth planning year. However, the electrical energy received from utility grid decreases $1.75 \times 10^{6} \mathrm{kWh}$ corresponding with $29.41 \%$ when two PV modules are installed in the seventh year. In the eighth year, one WT module is installed with a rated power $510 \mathrm{~kW}$ and thus this reduction increases to $3.0 \times 10^{6} \mathrm{kWh}$ each year corresponding with $48.08 \%$ in the eighth year, $46.19 \%$ in the ninth year and $44.19 \%$ in the tenth year.

Because of reasons above, the $\mathrm{CO}_{2}$ emission decreases from $34.6 \times 10^{3}$ tons in the case without RES to $28.11 \times 10^{3}$ tons in the case with RES. Hence, it is decreased about $6.49 \times 10^{3}$ tons along with the emission tax that is reduced by $25.97 \times 10^{3} \$$ during the planning period as shown in table 4 . In addition, the LCC of the project reduces about $0.22 \mathrm{M} \$$ corresponding to $5.98 \%$ although the investment cost of the RES is high and equal $0.81 \mathrm{M} \$$ at net present value. 
Table 4. Comparison of economic and technical indicators of planning project in two cases

\begin{tabular}{llll}
\hline Economic and technical indicators & Without RES & $\begin{array}{l}\text { With } \\
\text { RES }\end{array}$ & $\begin{array}{l}\text { Comparison between with RES } \\
\text { case and without RES case }\end{array}$ \\
\hline Total life cycle cost, M\$ & 3.68 & 3.46 & -0.22 \\
Invested cost, M\$ & 0 & 0.81 & 0.81 \\
Total electrical energy purchased from utility grid, $10^{6} \mathrm{kWh}$ & 55.81 & 44.99 & -10.82 \\
$\mathrm{CO} 2$ emission, $10^{3}$ tons & 34.60 & 28.11 & -6.49 \\
Emission taxes cost, $10^{3} \$$ & 138,41 & 112.44 & -25.97 \\
\hline
\end{tabular}

The results above show that the effect of the RES in micro-grid planning is significant in both economic and technical indicators due to a reduction of both the LCC and emission. Moreover, the reliability of the micro-grids is also improved because of some portion of power for loads are still supplied by the RES when the utility grid is faulty. The reduction of the power received from the utility grid through PCC also defers upgrading the connectible equipment.

\section{CONCLUSIONS}

In this research, a multi-scenario planning framework for grid-connected micro-grid is presented with an examination of investment in RES with respect to the uncertainty parameters based on minimizing the LCC of the invested project. The proposed model features a number of important aspects:

The multi-scenario planning framework proposed with the objective function and constraints can determine the optimal number, rated power and technology of modules as well as installed time of the RES. The objective function is minimizing the LCC during the time of the project that includes the investment cost, operation and maintenance cost of the RES, the electrical energy purchased cost from the utility grid, the emission taxes cost and the replacement cost or residual value of equipment at the end of the planning period. Hence, the different lifetime and the uptime of the RES are examined which improve the accuracy and suitability of model for the practical planning problem.

The uncertainties of parameters are considered and modeled by the pdf, the K-means clustering technique is utilized to divide into different states with specific value and the related probability in each state to reduce the computational burden. Then, a combinable model integrates all the states of parameters such as the electrical price, load and the output power of the PV and WT.

The proposed model utilizes integer variables to perform the invested decision of the RES based on rated power of different modules that are discrete values. Therefore, the computed result determines the number of modules with rated power and type of them, which agree with the actual parameters.

The simulation results demonstrate how the high efficiency of the RES in planning grid-connected micro-grid because the RES could promote the reduction of LCC and the cost for purchasing electrical energy from the utility grid. Particularly, the emission of the micro-grid significantly decreases and that has great significance in the context of climate change today.

The cases study has illustrated the feasibility and effectiveness of the proposed model, which indicates that the RES have high efficiency in reducing the cost and emission, and the optimization method could be brought into practice.

\section{Acknowledgment}

This work is supported by Thai Nguyen University of Technology (TNUT), Vietnam, as parts of a scientific project. 


\section{REFERENCES}

[1] Prieto-Araujo, E, Olivella-Rosel, P, Cheah-Mañe, M, Villafafila-Robles, R, Gomis-Bellmunt, O. Renewable energy emulation concepts for microgrids. Renewable and Sustainable Energy Reviews 2015; 50: $325-345$.

[2] Kaur, S, Kaur, T. A Review of Microgrid Concept. International Journal of Advanced Research in Science, Engineering and Technology 2016; 3: 1513-1520.

[3] Chen, D, Xu, L. AC and DC Microgrid with Distributed Energy Resources. In: Veneri, Ottorino. Technologies and Applications for Smart Charging of Electric and Plug-in Hybrid Vehicles. Cham, Switzerland: Springer International Publishing Switzerland, 2017. pp. 39-64.

[4] Ahmed, M, Amin, U, Aftab, S, Ahmed, Z. Integration of Renewable Energy Resources in Microgrid. Energy and Power Engineering 2015; $7:$ 12-29.

[5] Theo, WL, Limb, JS, Ho, WS, Hashim, H, Lee, CT. Review of distributed generation system planning and optimisation techniques: Comparison of numerical and mathematical modelling methods. Renewable and Sustainable Energy Reviews 2017; 67: 531-573.

[6] Sambaiah, KS. A Review on Optimal Allocation and Sizing Techniques for DG in Distribution Systems. International Journal of Renewable Energy Research 2018; 8: 1236-1256.

[7] Singh, B, Sharma, J. A review on distributed generation planning, Renewable and Sustainable Energy Reviews 2017; 76: 529-544.

[8] IRENA, International Renewable Energy Agency, Renewable Power Generation Costs 2017, Abu Dhabi, UAE, 2017.

[9] Kapoor, P, Singh, MKR, Shashikant. A Review on Distributed Generation Definitions and DG Impacts on Distribution System. International Journal of Innovative Science and Modern Engineering 2017; 4: 1-6.

[10] Latreche, Y, Bouchekara, HREH, Kerrour, F, Naidu, K, Mokhlis, H, Javaid, MS. Comprehensive review on the optimal integration of distributed generation in distribution systems. Journal of Renewable and Sustainable Energy 2018; 10: 1-33.

[11] Mumtaz and Bayram, IS. Planning, Operation, and Protection of Microgrids: An Overview. Energy Procedia 2017; 107: 94-100.

[12] Gamarraa, C. and Guerrero, JM. Computational optimization techniques applied to microgrids planning: a review. Renewable \& Sustainable Energy Reviews 2015; 48: 413-424.

[13] Jing, Z, Zhu, J, Hu, R. Sizing optimization for island microgrid with pumped storage system considering demand response. J. Mod. Power Syst. Clean Energy 2018; 6: 791-801.

[14] Wang, Z, Chen, Y., Mei, S, Huang, S, Xu, Y. Optimal expansion planning of isolated microgrid with renewable energy resources and controllable loads. IET Renew. Power Gener. 2017; 11: 931-940.

[15] Lotfi, H, Khodaei, A. Co-Optimization Generation and Distribution Planning in Microgrids. In: IEEE International Conference on Smart Grid Communications; 23-26 October 2017: Germany, pp .1-6.

[16] Hernández, ACL, Aldana, NLD, Andrade, F, Graells, M, Guerrero, JM, Vasquez, JC. Economic Power Dispatch of Distributed Generators in a Grid-Connected Microgrid. In: ICPE-ECCE Asia. The 9th International Conference on Power Electronics and ECCE Asia; 1-5 June 2015: South Korea, pp. 1161-1168.

[17] Ahamdi, SP, Lordejani, SN ,Rahimi-Kian, A, Milasi, AM, Vahdati, PM. Uncertainty based configuration design and optimal operation of a grid-connected Micro-Grid. In: 2013 Smart Grid Conference (SGC), 17-18 December 2013: Iran, pp. 102-107.

[18] Fang, W, Liu, H, Chen, H, Zheng, H, Hua, G, He, W. DG planning in stand-alone microgrid considering stochastic characteristic. The Journal of Engineering 2017; 2017: 1181-1185.

[19] Gazijahani, FS, Salehi, J. Optimal Bi-level Model for Stochastic Risk-based Planning of Microgrids Under Uncertainty. IEEE Transactions on Industrial Informatics 2018; 14: 3054-3064.

[20] Khodaei, A, Bahramirad, S, Shahidehpour, M. Microgrid Planning Under Uncertainty. IEEE Transactions on Power Systems 2015; 30: 2417-2425.

[21] Jahangir, H, Ahmadian, A, Golkar, MA. Opyimal desigh of standalone micro-grid considering reliability and investment cost. In: CIRED Workshop; 14-15 June 2016: Helsinki, pp. 1-4.

[22] Nadimi, A, Adabi, F. Optimized Planning for Hybrid Microgrid in Grid-Connected Mode. International Journal of Renewable Energy Research 2016; 6: 494-503.

[23] Wand, C, Jiao, B, Guo, L, Yuan, K, Ssun, B. Optimal planning of stand-alone microgrids incorporating reliability. J. Mod. Power Syst. Clean Energy 2014; 2: 195-205.

[24] Liu, Z, Chen, Y, Luo, Y, Zhao, G, Jin, X. Optimized Planning of Power Source Capacity in Microgrid Considering Combinations of Energy Storage Devices. Appl. Sci. 2016; 6: 1-19.

[25] González, A, Riba, JR, Rius, A. Optimal Sizing of a Hybrid Grid-Connected Photovoltaic-Wind-Biomass Power System. Sustainability 2015; 7: 12787-12806. 
[26] Jasemia, M, Adabi, F, Mozafari, B, Salahi, S. Optimal Operation of Micro-Grids Considering the Uncertainties of Demand and Renewable Energy Resources Generation. Int. Journal of Renewable Energy Development 2016; 5: 233-248.

[27] Atwa, YM, El-Saadany, EF. Probabilistic approach for optimal allocation of wind based distributed generation in distribution systems. IET Renew. Power Gener. 2011; 5: 79-88.

[28] Atwa, YM, El-Saadany, EF, Salama, MMA, Seethapathy, R. Optimal Renewable Resources Mix for Distribution System Energy Loss Minimization. IEEE Transactions on Power System 2010; 25: 360-370.

[29] Zhao, B, Zhang, X, Chen, J, Wang, C, Guo, L. Operation Optimization of Standalone Microgrids Considering Lifetime Characteristics of Battery Energy Storage System. IEEE Transactions on Sustainable Energy 2013; 4: 934-943.

[30] Soroudi, A, Mohammadi-Ivatloo, B, Rabiee, A. Energy Hub Management with Intermittent Wind Power. Large Scale Renewable Power Generation. In: J. Hossain and A. Mahmud. Large Scale Renewable Power Generation, Green Energy and Technology. Cham, Switzerland: Springer International Publishing Switzerland, 2014. pp. 413-438.

[31] Thang, VV, Zhang, Y, Ha, TT, Liu, S. Optimal operation of energy hub in competitive electricity market considering uncertainties. International Journal of Energy and Environmental Engineering 2018; 9: 351-362.

[32] Liu, Z, Wen, F, Ledwich, G. Optimal Siting and Sizing of Distributed Generators in Distribution Systems Considering Uncertainties. IEEE Transactions on Power Delivery 2011; 26: 2541-2551.

[33] Catalogue of European Urban Wind Turbine Manufacturers, Wind Energy Integration in the Urban Environment (WINEUR) 2018, http://www.urbanwind.net/wineur.html.

[34] IRENA, Renewable Power Generation Costs in 2017, International Renewable Energy Agency, Abu Dhabi, pp. 1-158.

[35] Sollatek Solar Catalogue 2018, https://www.sollatek.com/product-category/solar-products/.

[36] Bayod-Rújula, AA, Yuan, Y, Martínez-Gracia, A, Wang, J, Uche, J, Chen, H. Modelling and Simulation of a Building Energy Hub. Proceedings 2018; 2: 1-6.

[37] Amir, V, Jadid, S, Ehsan, M. Optimal Planning of a Multi-Carrier Microgrid Considering Demand-Side Management. International Journal of Renewable Energy Research 2018; 8: 238-249.

[38] Gong, Q, Lei, J, Ye, J. Optimal Siting and Sizing of Distributed Generators in Distribution Systems Considering Cost of Operation Risk. Energies 2016; 9: 1-18.

[39] Deng, S, Wu, Q, Jing, Z, Wu, L, Wei, F, Zhou, X. Optimal Capacity Configuration for Energy Hubs Considering Part-Load Characteristics of Generation Units. Energies 2017; 10: 2-19.

[40] Chen, Z, Yan, Z. Scenario tree reduction methods through clustering nodes. Computers and Chemical Engineering 2018; 109: 96-111.

[41] Xu, D, Chen, Z, Yang, L. Scenario tree generation approaches using K-means and LP moment matching methods. Journal of Computational and Applied Mathematics 2012; 236: 4561-4579. 